\title{
VORTICAL VLF MOTIONS UNDER SHORE-NORMAL INCIDENT WAVES
}

\author{
Matthieu de Schipper ${ }^{1}$, Ad Reniers ${ }^{2}$, Jamie MacMahan ${ }^{3}$ and Roshanka Ranasinghe ${ }^{1,4}$ \\ Field observations and numerical model simulations are examined to investigate the magnitude of vortical very low \\ frequency (VLF) velocity fluctuations (i.e. large scale surfzone eddies) under different offshore wave forcing. \\ Observations of vortical VLF motions under shore -normal wave incidence at Duck, NC, USA are re-analyzed and \\ compared with the characteristics of the incident wave spectrum. Long wave periods and narrow frequency spread \\ incident waves were found to coincide with stronger vortical VLF motions. Numerical model simulations \\ investigating the effect of the incident wave parameters in a more isolated way confirm the observed effect of \\ frequency spread and wave period on the magnitude of VLF motions. Variations in incident wave spectrum resulted \\ in changes in the vortical VLF magnitude of the same order as the magnitude of the vortical VLF velocity \\ fluctuations themselves. These results imply that under shore-normal incident waves strong vortical VLF velocity \\ fluctuations in the surfzone are more likely under swell conditions and at swell dominated coasts.
}

Keywords: Surfzone hydrodynamics; low frequency motions; transient rip currents; surfzone eddies

\section{INTRODUCTION}

Vortical very low frequency (VLF) motions are slowly varying current fluctuations observed in the nearshore zone. As these velocity fluctuations originate from temporal and spatial variations in wave height, which are present at any coast, these fluctuations are hypothesized to be ubiquitous (MacMahan et al. 2010). The vortical VLF motions have spatial scales of $O(100 \mathrm{~m})$, time scales of $O$ (10 minutes) and are mostly found inside and close the surfzone (MacMahan et al. 2004, 2010). They are referred to as vortical as their observed alongshore length scale - frequency ratio falls outside the free surface gravity range, and hence these motions are classified to be eddies rather than travelling waves. Surfzone velocity fluctuations on this timescale can pose a risk to ocean bathers as offshore velocities can vary with as much as $0.5 \mathrm{~m} / \mathrm{s}$ on a short timescale. This can lead to strengthening of existing rip currents or the generation of transient rip currents (MacMahan et al. 2006, Johnson and Pattiaratchi 2004). Moreover, the eddy like behavior of vortical VLF motions is found to significantly affect the mixing of material (larvae, nutrients, pollutants) inside the surfzone (Spydell et al. 2007,2009) as well as the exchange of material with the shelf (Reniers et al. 2009,2010).

Surfzone current fluctuations on the VLF timescale have been observed under both oblique and shore-normal waves. Under oblique waves the fluctuations have been attributed to shear instability of the wave driven alongshore current (Bowen and Holman, 1989). Under shore normal waves these motions are hypothesized to be generated due to the oscillation of the 2D horizontal circulations (ripcells) (MacMahan et al. 2004) as well as finite crest length wave breaking turbulence cascading to larger length scales (Spydell and Feddersen, 2009). Both generation mechanisms proposed for VLF motions under shore-nomal incident waves point out that essentially the presence of directional and frequency spread in waves along a natural coast yield to the generation of vortical VLF motions.

Regardless of the exact origin, observations show that the magnitude of vortical VLF velocity fluctuations can vary significantly from day to day (MacMahan et al. 2004, 2010). Maximum reported values for the VLF velocity fluctuations are around $0.5 \mathrm{~m} / \mathrm{s}$. As can be expected, under higher incident waves, the magnitude of the VLF motions was found to increase. Yet, the existing observations of VLF magnitude show a large scatter, even for a single wave height at a particular beach. As VLF motions originate from directionally frequency spread waves we hypothesize that the type of wave conditions, swell or windsea, quantified by the shape of the incident wave spectrum does affect the size of the vortical VLF velocity fluctuations.

The objective of the current study is therefore to investigate the magnitude of the vortical VLF velocity fluctuations under shore-normal waves for various incident wave conditions and investigate whether the magnitude is dependent on the type of wave conditions. This is done using a twofold approach; first field observations of VLF motions of Duck, NC are reanalyzed to investigate a

\footnotetext{
${ }^{1}$ Coastal Engineering, Section of Hydraulic engineering, Delft University of Technology, Delft, The Netherlands.

${ }^{2}$ Rosenstiel School of Marine and Atmospheric Science (RSMAS), University of Miami, Miami, USA.

${ }^{3}$ Oceanography Department, Naval Postgraduate School, Monterey, California, USA.

${ }^{4}$ UNESCO-IHE Institute for Water Education, Delft, The Netherlands
} 
dependency on offshore forcing. Secondly, in a more schematized approach the impact of frequency and directional spread is tested independently using numerical model simulations.

\section{FIELD OBSERVATIONS}

\section{Dataset description}

The dataset used for the analysis was obtained during the 4 month SandyDuck97 field campaign at Duck, NC, USA. During the experiment an extensive array of instruments was deployed in the nearshore, capable of capturing both the wave transformation as well as the surfzone hydrodynamics (Elgar et al, 2001). The instrument data used here were obtained from five alongshore arrays (A1 to A5) and a large cross-shore array C1 of SPUV (collocated Sonar altimetry, Pressure and EM flow velocity $u$ and $v$ ) sensors (Fig. 1). The instruments recorded data in runs of 3 hours, sufficiently long to investigate surfzone motions on the VLF timescale of $O 10$ minutes.

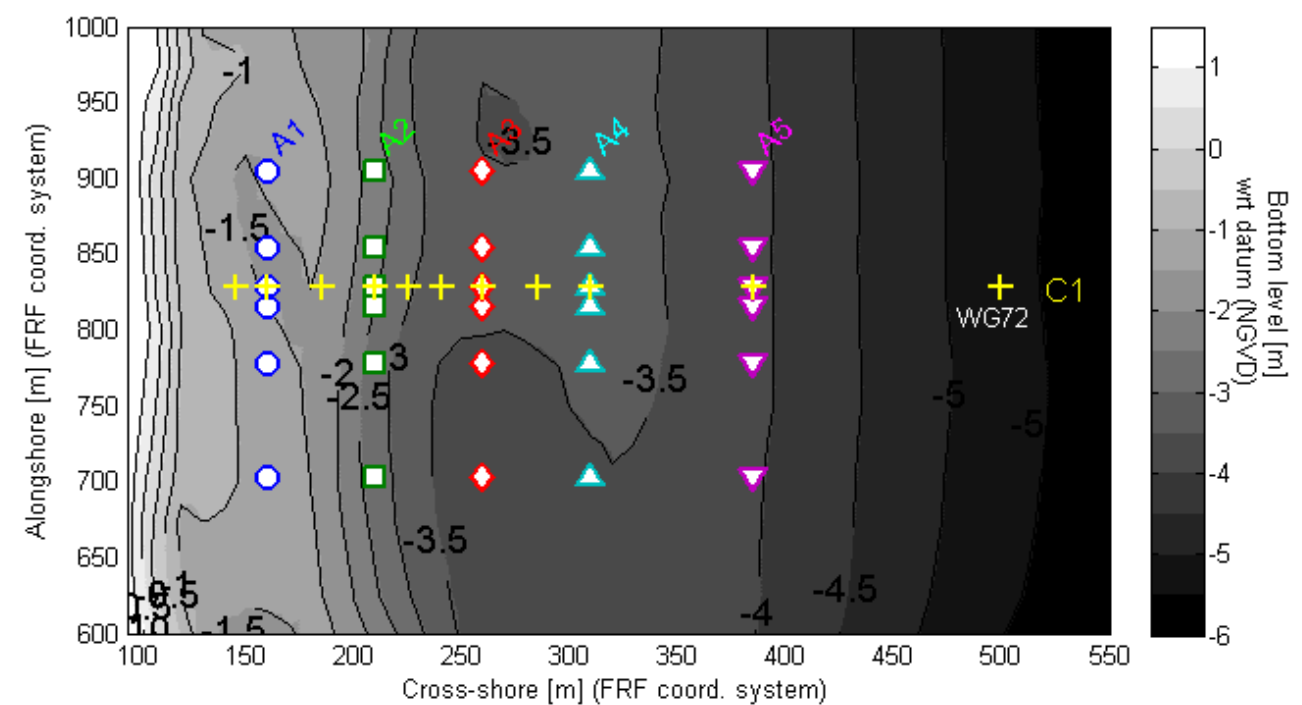

Figure 1. Overview of the Sandy duck instrument layout. Blue circles indicate SPUV locations of the most shoreward alongshore array A1, Green squares show array A2. Large cross-shore transect of sensors $\mathrm{C1}$ indicated by the yellow crosses. Bottom topography as measured on October $30^{\text {th }} 1997$.

Offshore wave conditions were recorded during the campaign by an array at approximately $8 \mathrm{~m}$ water depth and converted to two dimensional frequency-directional spectra by the Field Research Facility (FRF) (Long and Atmadja, 1994). The water depth at the SPUV gauges was obtained using the sonar altimeter data of the SPUVs combined with the tidal elevation recorded at the National Oceanic and Atmospheric Administration (NOAA) tide station located at the seaward end of the FRF pier.

\section{Data processing}

The SPUV instrument data are processed as described in MacMahan et al. (2010). For completeness the methodology is repeated here. During the 4 months of the SandyDuck campaign (i.e. about 950 time periods of 3 hours), a wide variety of forcing conditions occurred. A selection is made to eliminate periods with significant alongshore current, hereby avoiding instants where VLF motions were generated and/or affected by alongshore current (shear) instabilities. Similar to Macmahan et al. (2010), time periods were discarded when $0.25 \mathrm{~m} / \mathrm{s}$ alongshore velocity or more was observed at any of the SPUV's in the cross-shore array C1. Approximately half of the time periods (440 bursts of 3 hours) remained after this selection.

The magnitude of the vortical VLF motions was calculated for the alongshore arrays A1 to A5. The alongshore coherent arrays used at SandyDuck enable to obtain an estimate of the alongshore length scale $k_{y}$ of (low frequency) motions. In a 2 dimensional spectral analysis (Maximum Likelihood Estimator; MacMahan et al, 2010 and references therein) the recorded flow velocities were separated per alongshore array into 2D energy spectra $G_{u u}\left(f, k_{y}\right)$ and $G_{v v}\left(f, k_{y}\right)$ of the cross and alongshore velocities respectively. These velocity spectra contain a segment with energy with small alongshore wavenumbers related to predominantly cross-shore motions of waves. The regions of the $f, k_{y}$ spectra with larger alongshore wavenumbers reflect alongshore traveling waves and vortical (eddy like) motions. Vortical 
motions were separated using the shallow water dispersion relation $\left(k_{y}=f / \sqrt{g d}\right.$, with $d$ being the local waterdepth) as the boundary between the free surface gravity waves and vortical motions (See also Fig. 7). The magnitude of vortical VLF motions was then quantified by integrating the energy of both $G_{u u}$ and $G_{v v}$ for the vortical VLF regions (i.e. outside the dispersion relation curve):

$$
\begin{aligned}
q_{\text {VortVLF,rms }}= & \int_{-0.04 m^{-1}}^{-k_{y g}} \int_{0.0005 H z}^{0.004 H z}\left[G_{u u}\left(f, k_{y}\right)+G_{v v}\left(f, k_{y}\right)\right] d f d k_{y} \\
& +\int_{k_{y g}}^{0.04 m^{-1}} \int_{0.0005 H z}^{0.004 H z}\left[G_{u u}\left(f, k_{y}\right)+G_{v v}\left(f, k_{y}\right)\right] d f d k_{y} .
\end{aligned}
$$

The calculated vortical VLF magnitude $q_{\text {VortVLF,rms }}$ at the most shoreward array A1 is shown in Fig. 2 for the full 4 month period. In total 235 time periods were found with both negligible alongshore current and vortical VLF motions ( $q_{\text {VortVLF,rms }}>0 \mathrm{~m} / \mathrm{s}$ ) (filled circles in Fig. 2).

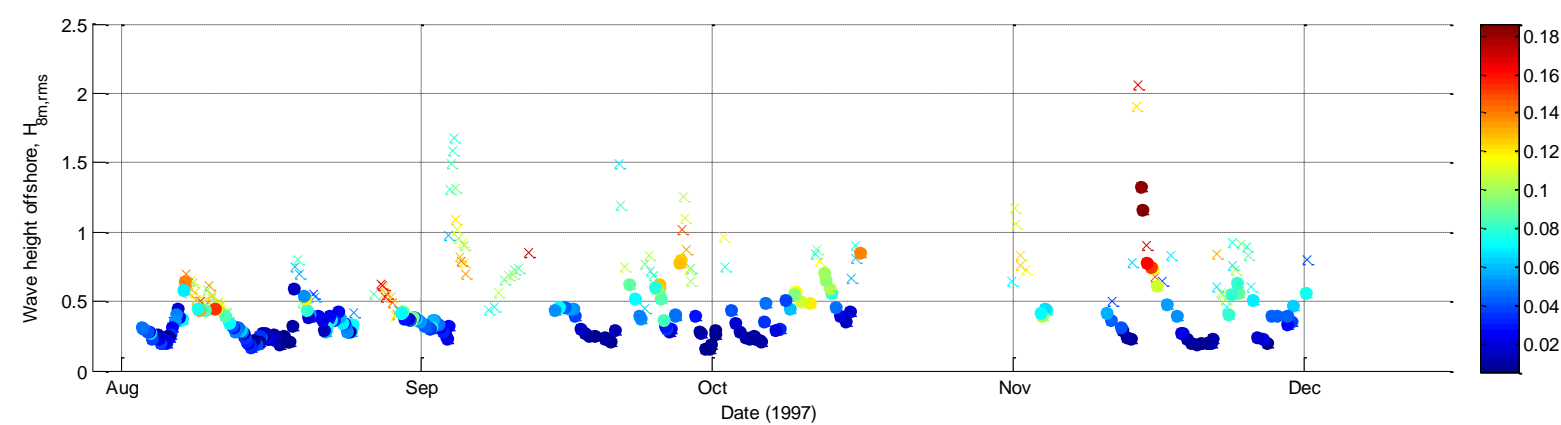

Figure 2. Vortical VLF magnitude as observed during 4 months of Sandy Duck at array A1. Colors indicate $q_{\text {VortVLF,rms }}$ values, warm (red) colors coincide with large Vort VLF motions (up to $0.18 \mathrm{~m} / \mathrm{s}$ ), blue colors indicate hardly any vortical VLF motions. Filled circles represent time period with negligible alongshore current, crosses are periods with alongshore current.

Most of the periods when vortical VLF motions were observed the incoming wave height was small, mean $H_{r m s, 8 m}$ over all these periods equals $0.4 \mathrm{~m}$. Bottom level at the array A1 is typically around -1.3 below datum which, combined with the tidal range of $1 \mathrm{~m}$, implies that the array was located outside the surfzone for most periods vortical VLF motions were observed. A final selection was therefore made, restricting the observations only to time periods when waves were breaking at array A1. Using the large cross-shore array of sensors $\mathrm{C} 1$ (Fig. 1), the wave transformation was analyzed. The most shoreward alongshore array A1 was assumed to be within the surfzone if a small decrease in wave height was observed from A2 to A1 $\left(H_{r m s, x=160 m} \leq H_{r m s, x=210 m}-0.04 m\right)$. This last selection greatly reduces the amount of data points to 22 , but ensures that the observations are inside the surfzone. As time periods when A1 was outside the surfzone are rejected, it also provides more certainty that VLF motions are not generated or impacted by a large wave driven alongshore current in the surfzone shoreward of the array A1. The wave height along the cross-shore array $\mathrm{C} 1$ is shown in Fig. 3 for the 22 retained time periods. Array A1 was located at the edge of the surfzone for all runs, except for the two time periods with the largest incident wave heights for which waves were breaking far offshore around $x \sim 350 \mathrm{~m}$. 


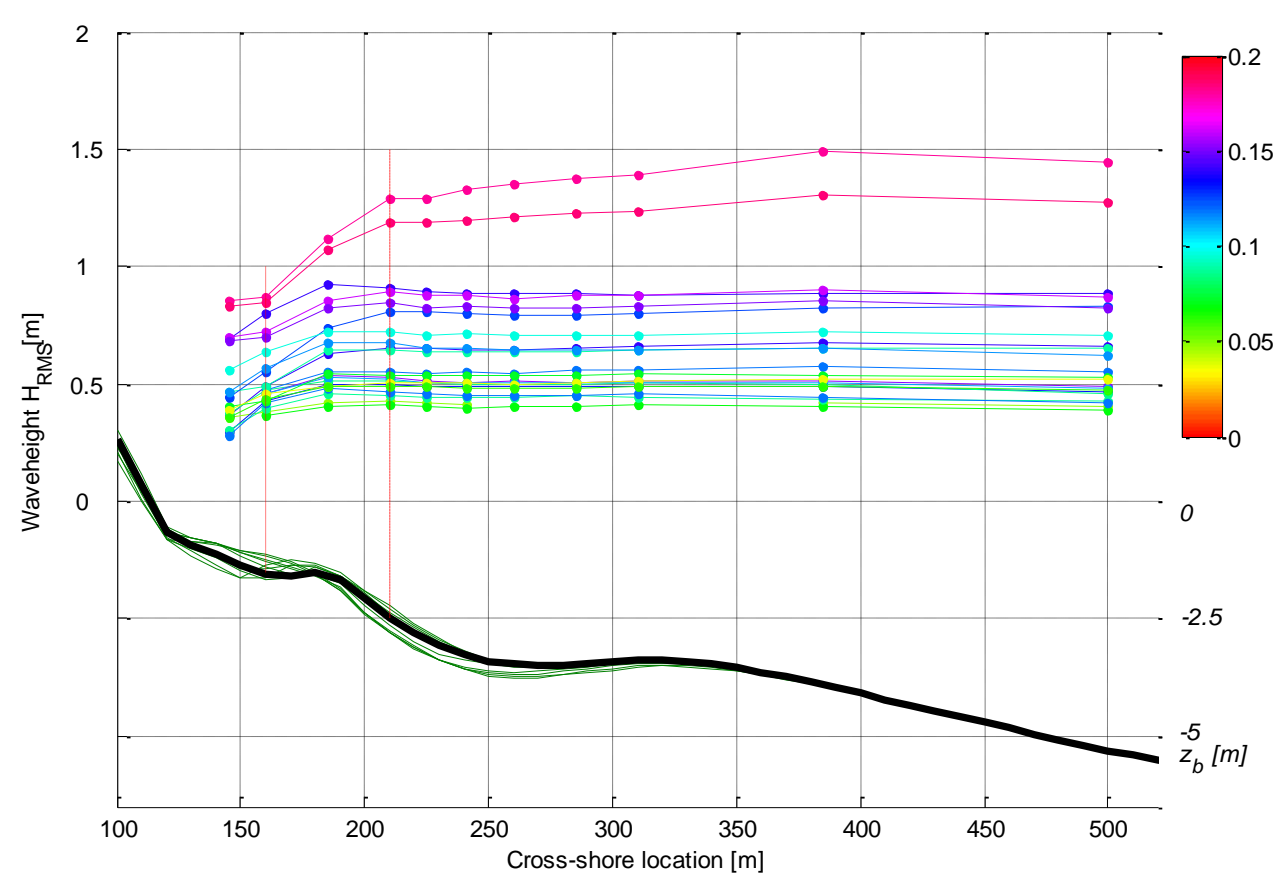

Figure 3. Wave transformation along cross-shore array $\mathrm{C} 1$ for the selected time periods with surfzone Vort VLF observations. The location of alongshore array A1 (A2) is indicated by the dotted (dash-dotted) line. Colors indicate $q_{V o r t V L F, r m s}$ values. Topography profile as measured on October $30^{\text {th }} 1997$ at transect $\mathrm{C} 1$ in black, adjacent profiles in the instrumented area in dark green.

Next, concurrent incident wave conditions were analyzed for mean period, frequency and directional spread. Wave period was expressed in a mean period $T_{m}$, calculated as inverse of the mean frequency $f_{m}$ as observed at the $8 \mathrm{~m}$ array. The directional spread of the offshore forcing was calculated from the frequency directional spectra $E(f, \theta)$ also calculated at the $8 \mathrm{~m}$ array. The directional distribution (over all frequencies) was obtained following $D(\theta)=\frac{E(f, \theta)}{E(f)}$, with $E(f)$ being the one dimensional frequency spectrum. The bulk directional spread of the incident spectra was then expressed by $\sigma_{\theta}$ :

$$
\sigma_{\theta}=\sqrt{\int_{-\pi / 2}^{\pi / 2}\left(2 \sin \left(\theta-\theta_{0}\right) / 2\right)^{2} D(\theta) d \theta}
$$

Expression $\left(\sigma_{\theta}\right)$ used here is similar to the bulk parameter for directional spread $\sigma_{\theta}^{*}$ as proposed in Kuik et al. (1988). Typical values for $\sigma_{\theta}$ at Duck, NC are between 16 to 32 degrees (Feddersen, 2004).

The frequency spread of the spectra was expressed by parameter $\kappa$ (VanVledder, 1992), which was calculated from the short wave spectrum $E(f)$ using:

$$
\begin{gathered}
\kappa=\frac{1}{m_{0}^{2}}\left[\int_{0.045 H z}^{0.32 H z} E(f) \cos \left(\frac{2 \pi f}{\bar{f}_{0}}\right) d f\right]^{2}+ \\
\frac{1}{m_{0}^{2}}\left[\int_{0.045 \mathrm{~Hz}}^{0.32 H z} E(f) \sin \left(\frac{2 \pi f}{\bar{f}_{0}}\right) d f\right]^{2}
\end{gathered}
$$


where $\bar{f}_{0}$ is the zero crossing frequency $\sqrt{m_{2} / m_{0}}, m_{n}$ being the $n$-th order moment of the frequency spectrum $E(f)$. As spectral information of the $8 \mathrm{~m}$ array was not available from the $8 \mathrm{~m}$ array for the August and December, $\kappa$ was calculated from the most seaward SPUV (WG72) at approximately $5 \mathrm{~m}$ waterdepth ( Fig. 1). Calculated values of $\kappa$ are in the range 0.1 (wide) to 0.6 (narrow freq. spread). Typically spectra were quite wide with energy spread around the peak. On some occasions the presence of superharmonics (e.g. Guza and Thornton, 1980) may cause the spectra to appear wider in bulk spread parameters than they actually are. Visual inspection of the observed frequency directional spectra however revealed that most spectra were just wide rather than multiple peaked at the harmonic frequencies.

\section{Field data results}

The observations of vortical VLF magnitude in the surfzone were compared to the characteristics of the concurrent incident wave forcing. In general, VLF magnitude is found to be larger under high incoming wave heights, as reported previously (MacMahan et al. 2004, 2010 or Fig. 2). Yet for a single incident wave height a wide range of VLF magnitudes is reported. We investigated whether 'swell' conditions (long wave period, narrow frequency and directional spread) yield to different VLF magnitude. Vortical VLF magnitude is plotted here versus two wave energy proxies:

- The incoming offshore wave height $H_{r m s, 8 m}$. The underlying hypothesis is that the total amount of wave energy dissipation in the surfzone determines the magnitude of the observed VLF motions regardless of the waterlevel (or surfzone width) and the wave breaking intensity.

- And secondly, the local energy dissipation at A1. Using the underlying hypothesis that the magnitude of VLF motions is dependent on the local wave breaking. This is especially interesting as the waterdepth at the instruments is variable in the field due to the varying topography and the tide. As such an incident wave height e.g. $H_{r m s}=0.8 \mathrm{~m}$ at $8 \mathrm{~m}$ offshore can lead to substantially different wave heights inshore at A1 depending on the time period (See also Fig. 3).

Figure 4 shows side by side the magnitude of vortical motions against both offshore waveheight (left panels) and dissipated energy (right panels). Dissipated wave energy is presented here as $\sqrt{H_{A 2}^{2}-H_{A 1}^{2}}$ for a comparison with the same proportionality as the other panels (in [m]).

Vortical VLF magnitude was found to be related to both incoming wave height $\left(R^{2}=0.5\right)$ as well as the dissipated energy $\left(R^{2}=0.55\right)$, but the small amount of observations prevents hard statements whether any of the two is more appropriate. The slightly better correlation when using local wave energy dissipation rather than incident wave height is thought to be mostly attributed to periods with offshore waveheights of $O 0.5 \mathrm{~m}$ under which a wide variety of vortical VLF maginitudes and wave height decrease over the sensors (Fig.3) was observed.

Bulk wave characteristics wave period, frequency spread and directional spread are given in Figure 4 in colors to show their relation to the observed Vort VLF magnitude. Observations point toward a dependency of the vortical VLF magnitude on type of wave conditions. For both wave period and frequency spread the data clouds show sorting. Red colored data points (representing more 'swell like' conditions) tend to be on the upper half of the data cloud. This implies that for a single waveheight larger VLF motions coincide with higher wave period and/or narrow frequency spread conditions. Data points colored to directional spread do not result in a clear sorting in colors, consequently no clear effect of the directional spread was found from this dataset.

The limited amount of data, changing (3D) topography and the dependency on multiple parameters make it difficult to draw firm conclusions based on the field data alone. To investigate the impact of VLF motions in a more isolated way, numerical model simulations where executed next. Bulk parameters of the forcing were tested independently of each other and topographic variability (in time and space) is removed. 

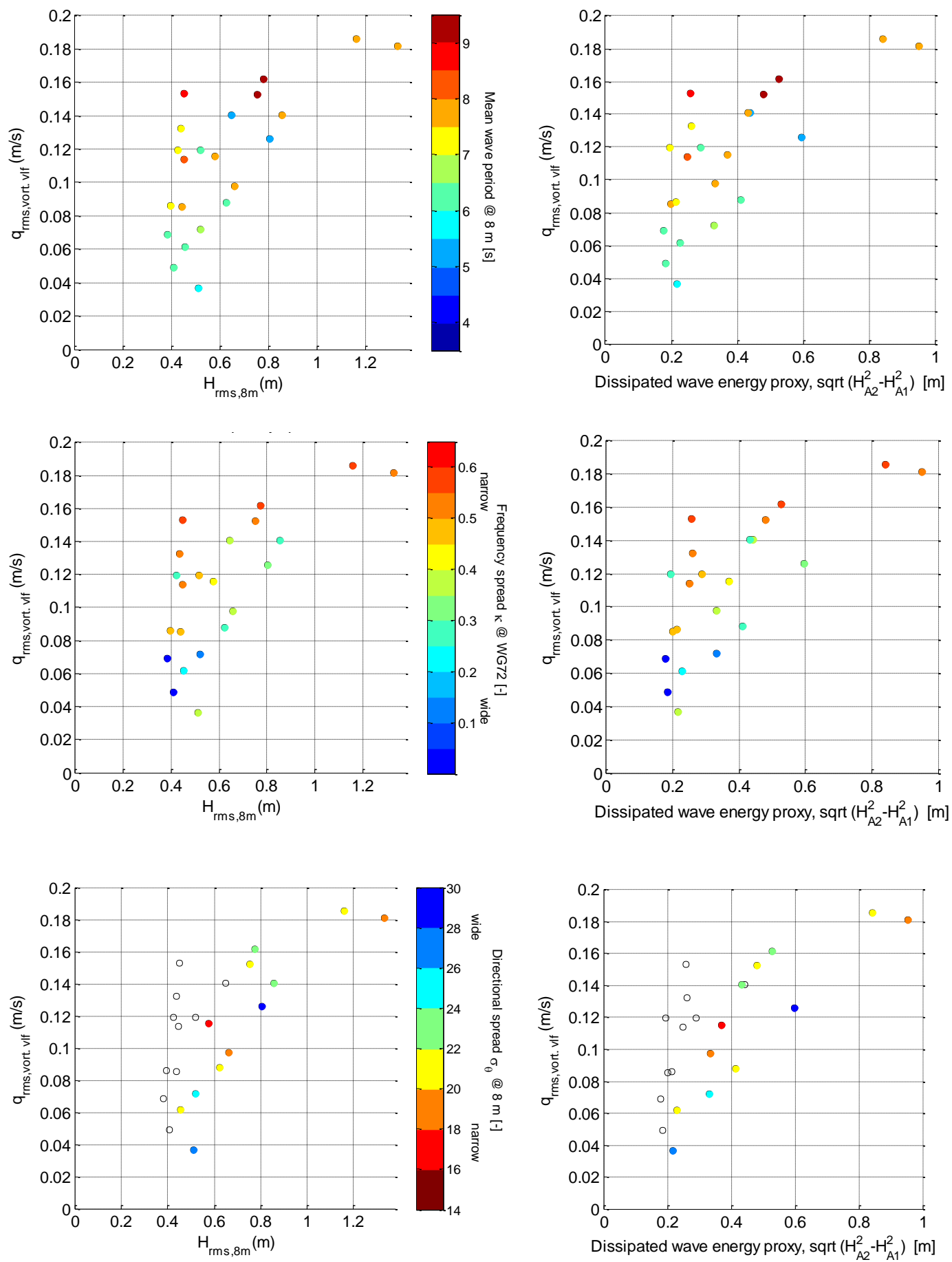

Figure 4. SandyDuck97 Vortical VLF observations sorted to mean period (top), frequency spread (middle) and directional spread (bottom). Left column figures show the observations plotted against the incident wave height, right column as function of the local dissipated energy. Warm (red) colors represent narrow banded long period waves typically associated with swell waves. Open circles represent time periods with no data on $\sigma_{\theta}$. 


\section{NUMERICAL MODEL SIMULATIONS}

The magnitude of vortical VLF motions was investigated for different scenarios of incident wave conditions using a 2DH (depth-averaged coastal area) numerical flow model. The model, a research version of Delft3D, solves the depth-averaged nonlinear shallow water equations. The model is short wave averaged but incorporates wave group forcing. This short wave averaged, long wave approach was found capable to resolve the mean surfzone flow as well as the low frequency flow associated with low frequency (infragravity) waves and VLF motions (Reniers et al., 2004, 2007). A complete model description and laboratory validation is given in Reniers et al. (2004) and model settings are similar to the settings used therein, unless stated otherwise.

\section{Model description}

The model configuration consists of three parts: 1 . the construction of the time and spatially varying offshore boundary conditions, 2 . a wave refraction model calculating the wave propagation direction, and 3. the wave and flow model, calculating the propagation and dissipation of the offshore wave energy and the resulting (surfzone) hydrodynamics. (Fig. 5).

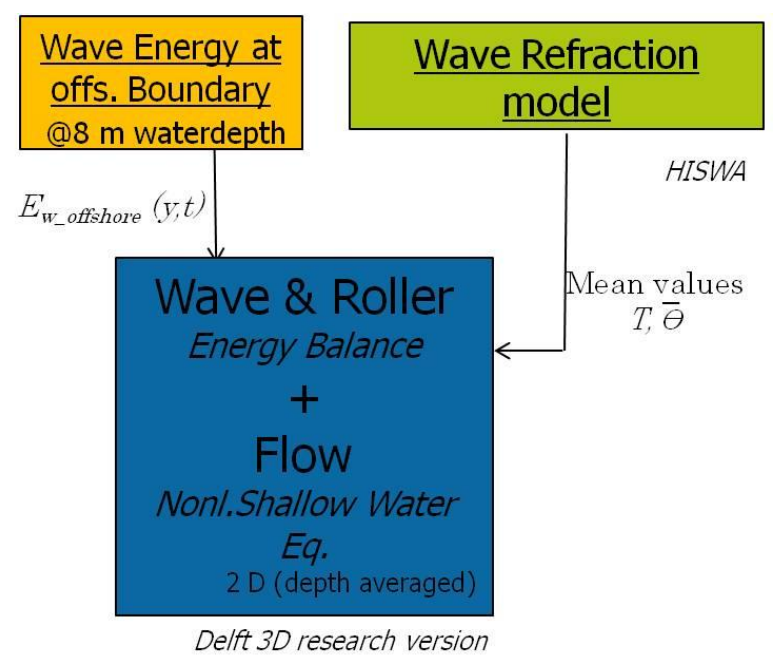

Figure 5. Conceptual figure of the numerical model setup.

The hydrodynamic model is forced at the offshore boundary with time and alongshore varying wave group energy $E_{w, \text { offshore }}(y, t)$. These synthetic timeseries of wave energy are sampled using the twodimensional frequency-direction short wave spectrum. As this part is used to generate scenarios for the investigation of the effect of wave period, frequency and directional spread, it will be elaborated hereunder.

The two-dimensional frequency-direction short wave spectrum was constructed from the Cartesian product of the frequency and directional distributions:

$$
E_{s w}(f, \theta)=D(\theta) \times E_{s w}(f),
$$

The frequency short wave spectrum $E_{s w}(f)$ herein was based on a JONSWAP formulation (Holthuijsen, 2007):

$$
E_{s w}(f)=\alpha g^{2}(2 \pi)^{-4} f^{-5} \exp \left[-\frac{5}{4}\left(\frac{f}{f_{p}}\right)^{-4}\right] \gamma^{\exp \left[-\frac{1}{2}\left(\frac{f / f_{p}-1}{\sigma}\right)^{2}\right],}
$$

where $g$ is the gravitational constant, $\alpha$ is a scale parameter and $\sigma$ is the peak enhancement width parameter. The most right hand term of Eq. 5 is a peak enhancement function $\gamma^{\exp \left[-\frac{1}{2}\left(\frac{f / f_{p}-1}{\sigma}\right)^{2}\right]}$, where $\gamma$ is 
usually chosen to be equal to 3.3 (Holthuijsen, 2007). Varying $\gamma$ makes it possible to adapt the frequency spread of the spectrum while keeping the total amount of wave energy constant. Using $\gamma$ equal to 1.0 in the JONSWAP formulation results in a standard Pierson-Moskowitz spectrum which is relatively wide (directional spread $\kappa=0.42$ ). Larger values of $\gamma$ lead to an increase of the peak enhancement function and consequently to more narrow-banded spectra (high $\kappa$ values).

The normalized directional distribution $D(\theta)$ in Eq. (4) was calculated as follows:

$$
D(\theta)=A^{*} \cos ^{s}(\theta),
$$

where exponent $s$ controls the directional width of the spectrum and parameter $A^{*}$ was chosen such that the total amount of energy is conserved.

Different seastate short wave spectra, ranging from swell to wind sea, were generated by varying $f_{p, \gamma}$, and $s$ in Eq. 5 and 6. The resulting two-dimensional frequency-direction spectra $E_{s w}(f, \theta)$ were used to generate synthetic short wave surface elevation $\eta(y, t)$ timeseries with a random phase approach (VanDongeren et al., 2003). The envelope of the surface elevation $A_{\text {env }}(y, t)$ follows the fluctuation of the wave energy on wave group scale and is computed using a Hilbert transform followed by a low pass filter $\left(f_{\text {cutoff }}=0.04 \mathrm{~Hz}\right)$. Finally, this wave group envelope is transformed into wave group energy using:

$$
E_{w, o f f s h o r e}(y, t)=\frac{1}{2} \rho g\left[A_{\text {env }}(y, t)\right]^{2},
$$

where $\rho$ is the density of water. This time and spatially varying wave group energy $E_{w, o f f s h o r e}(y, t)$ is imposed along the offshore boundary.

Mean angle $\bar{\theta}(x, y)$ of wave energy propagation throughout the domain is calculated using a wave refraction model (HISWA, Holthuijsen et al., 1989). Wave energy at the boundary $E_{w, o f f s h o r e}(y, t)$ and the wave angle $\bar{\theta}(x, y)$ are used next to propagate energy shoreward in the hydrodynamic flow module (see Fig .5). In this module the dissipation of wave energy due to breaking (including roller lag effects) and the resulting radiation stress forces are calculated. These forces $F_{x}, F_{y}$ are imposed on the 2D nonlinear shallow water equations resulting in surface elevations $\eta(x, y, t)$ and flow velocities $u(x, y, t)$, $v(x, y, t)$ on the long wave time scale (Reniers et al., 2004).

\section{Model schematization}

The wave forcing scenarios were tested on a schematized alongshore uniform single barred beach. The dimensions of the beach are $1.5 \mathrm{~km}$ in alongshore direction and almost $1.3 \mathrm{~km}$ in cross-shore. The beach profile is alongshore uniform with a single subtidal bar (Fig. 6) and unerodable. The subtidal bar crest is located $115 \mathrm{~m}$ from the shoreline $(x=190 \mathrm{~m})$ and bar crest height is $1.2 \mathrm{~m}$ below the still water level. Grid sizes are $10 \mathrm{~m}$ in alongshore and ranging from 4 to $25 \mathrm{~m}$ in the cross-shore direction depending on the water depth. Lateral boundaries are closed (mimicking an embayed beach case) and weakly reflective Riemann boundary is applied at offshore boundary to enable outgoing long waves to leave the domain. 

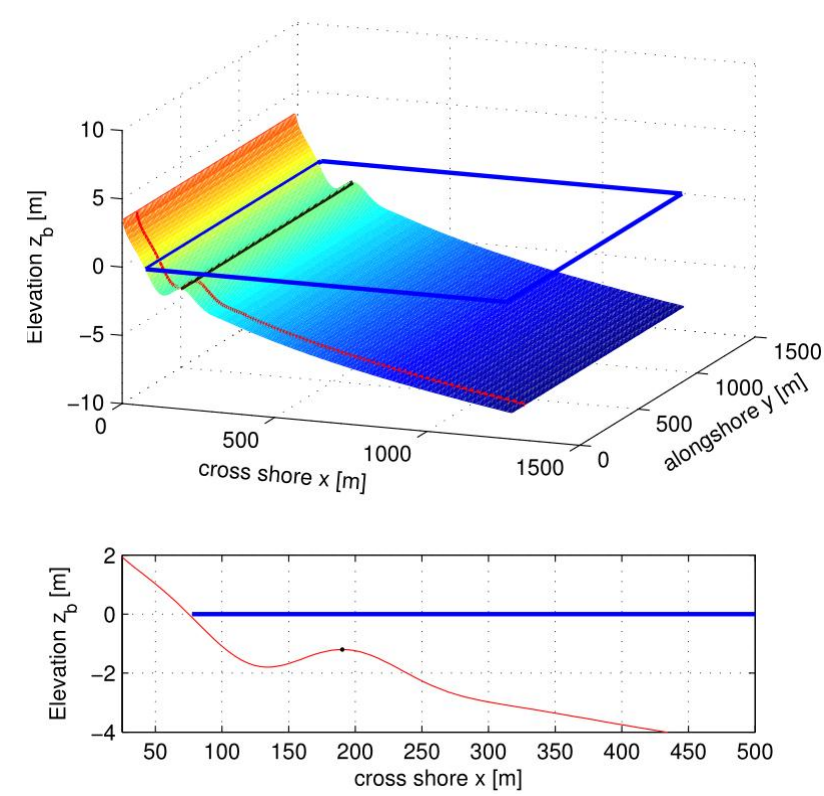

Figure 6. Bottom topography as used in the model. Top panel shows the full model domain, bottom panel shows a detailed transect of the nearshore. Still water line indicated by the blue lines, bar crest given by the black line.

\section{Scenarios}

Several wave scenarios are simulated exploring a range of natural conditions (Table 1). To compare different scenarios, the incoming offshore energy flux was equal for the tests. In scenario tests with modified wave period this required a slight adjustment of the wave height. For all other simulations with wave periods of $10 \mathrm{~s}$ the wave height offshore $H_{r m s} 8.1 \mathrm{~m}$ was equal to $1.0 \mathrm{~m}$. To investigate the effect of a single parameter individually, frequency and directional spread are varied independently.

\begin{tabular}{|c|c|c|c|c|c|}
\hline $\begin{array}{l}\text { Wave height, } \\
H_{\text {rms } 8.1 \mathrm{~m}} \\
{[\mathrm{~m}]}\end{array}$ & $\begin{array}{l}\text { Wave } \\
\text { period, } T_{p} \\
{[\mathrm{~s}]}\end{array}$ & $\begin{array}{l}\text { Frequency } \\
\text { spread, } \kappa \\
{[-]}\end{array}$ & $\begin{array}{l}\text { Directional } \\
\text { spread, } \sigma_{\theta} \\
\text { [degrees] }\end{array}$ & $\begin{array}{l}\text { Mean wave } \\
\text { angle, } \bar{\theta} \\
\text { [degrees] }\end{array}$ & $\begin{array}{l}\text { Offshore energy } \\
\text { flux, } P_{8.1 \mathrm{~m}} \\
{[\mathrm{~W} / \mathrm{m}]}\end{array}$ \\
\hline \multicolumn{6}{|c|}{ Reference simulation } \\
\hline \begin{tabular}{l|l}
1.0 \\
$\mid$
\end{tabular} & 10 & 0.57 & 12.2 & 0 & $9.510^{3}$ \\
\hline \multicolumn{6}{|l|}{ Wave period } \\
\hline 1.09 & 7 & 0.57 & 12.2 & 0 & $9.510^{3}$ \\
\hline 0.96 & 14 & 0.57 & 12.2 & 0 & $9.510^{3}$ \\
\hline \multicolumn{6}{|l|}{ Frequency Spread } \\
\hline $\mid 1.0$ & 10 & 0.42 & 12.2 & 0 & $9.510^{3}$ \\
\hline 1.0 & 10 & 0.72 & 12.2 & 0 & $9.510^{3}$ \\
\hline \multicolumn{6}{|l|}{ Directional Spread } \\
\hline $\mid 1.0$ & 10 & 0.57 & 7.3 & 0 & $9.510^{3}$ \\
\hline 1.0 & 10 & 0.57 & 12.2 & 0 & $9.510^{3}$ \\
\hline 1.0 & 10 & 0.57 & 18.2 & 0 & $9.510^{3}$ \\
\hline 1.0 & 10 & 0.57 & 23.4 & 0 & $9.510^{3}$ \\
\hline
\end{tabular}

For each simulation, the hydrodynamics are modeled for a total of 180 minutes with a hydrodynamic time step of 2.4 seconds. Horizontal and vertical tides are omitted, as well as wind driven flows. Boundary conditions are sampled using random phases and therefore each simulation is only a single possible realization of the nearshore flow under the imposed bulk forcing conditions. Repetitive tests of the same scenario show that although realizations are different, 3 hour bulk statistics of low frequency motions are hardly changed. 


\section{Post- processing}

Model results of the velocities in the domain are postprocessed to obtain the part of the velocity signal that can be attributed to low frequency motions. The first 30 minutes of each simulation contained spin up effects of the initial conditions and are discarded for further analysis. Of the remaining $2 \mathrm{~h} 30$ hours, timestacks of $u$ and $v$ in $(y, t)$ are extracted at the bar crest $(x=190 \mathrm{~m})$. The bar crest is located well within the surfzone for all computations as the waterdepth over the bar is $1.2 \mathrm{~m}$. The velocity timestacks were the analyzed with a two dimensional FFT analysis revealing the alongshore length $\left(k_{y}\right)$ and the temporal scale $(f)$ of the surfzone velocity motions. Fig 7 shows the distribution of energy in $f, k_{y}$ space obtained using the 2dFFT method for the model output of the reference simulation. In these model results velocity fluctuations in the IG frequencies $(0.004<f<0.04$ $\mathrm{Hz})$ are predominantly visible around the $k_{y}=0$ axis. These are related to the incoming and reflected long waves. Very low frequency $(f<0.004 \mathrm{~Hz})$ velocity fluctuations appear as two distinct spots of energy off-center around $k_{y}=0.005$ indicating an alongshore length scale of $O(200 \mathrm{~m})$. Similar to observations in the field (MacMahan et al. 2004, 2010), the majority of the VLF motions are in the vortical region of the $f, k_{y}$ space.

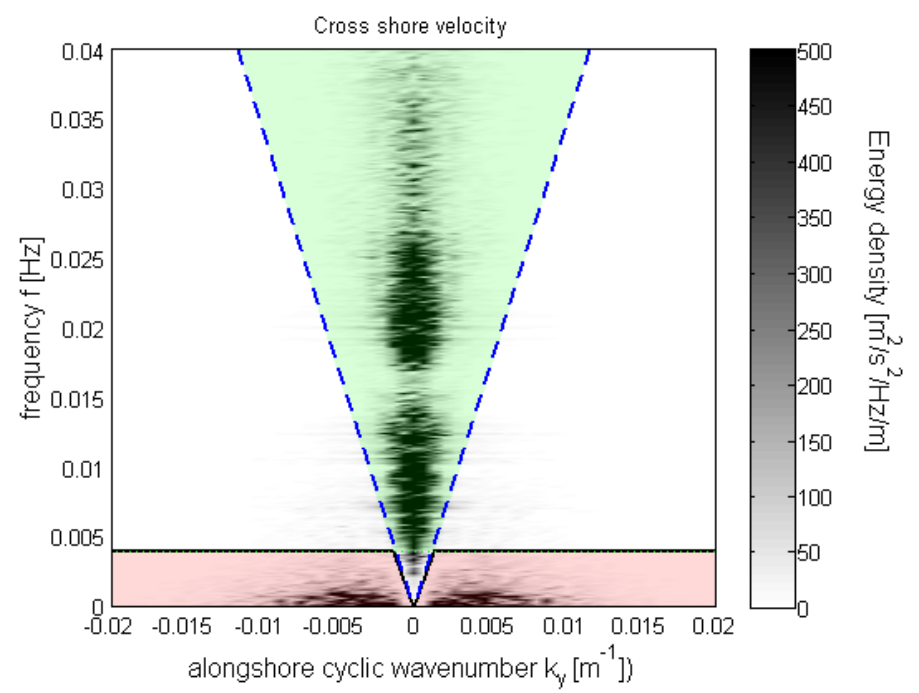

Figure 7. Frequency- alongshore wavenumber spectra of the computed cross-shore velocities on the bar crest. Blue dashed line shows the shallow water dispersion relation. Red and green colors mark the areas used to determine the magnitude of vortical VLF and non-vortical IG motions respectively.

The velocity signals were separated into vortical (eddy like) and non-vortical (wave like) using a division based on the shallow water dispersion relation. Identical to the Sandy Duck observations, the vortical VLF magnitude $q_{V o r t V L F, r m s}$ is computed by integrating the energy in the vortical energy part of the spectrum (Fig. 7, red areas and Eq. 1). Energy in the infragravity (IG) velocity fluctuations $q_{\text {nonvortIGrms }}$ was also calculated using a similar expression (Fig.7 green area).

\section{Model simulation results}

Velocity components as derived from the simulations are shown in Figure 8 sorted per spectral parameter. Results showed that the bulk parameters of the short wave field (short wave period $T_{p}$, frequency spread $\kappa$ and directional spread $\sigma_{\theta}$ ) have different effect on the magnitude of the VLF velocity fluctuations on the bar crest. The magnitude of non-vortical IG velocity is shown here as a reference to observe if the ratio between these motions was constant. Model results showed that this is not the case and the magnitude of vortical VLF motions was not as such proportional to the non-vortical IG motions on the bar crest.

Variations in wave period $T_{p}$ affected the magnitude of both IG and vortical VLF motions. Vortical VLF motions were found to increase under higher incident wave periods, similar to the findings of the SandyDuck observations (Fig. 4). Infragravity flow velocity more than doubled when period $T_{p}$ was increased from 7 to $14 \mathrm{~s}$. This was related to a combined effect of the generation of higher incoming 
bound long waves (Longuet-Higgins and Stewart, 1962) and an increase of the relative slope of the shore (Battjes et al., 2004). Frequency spread was found to hardly affect the magnitude of IG velocity fluctuations. Yet, model predictions show a significant increase in vortical VLF motions under narrower frequency spreads. Directional spread was predicted to reduce the IG motions significantly, as discussed in Sand (1982). However, on the vortical VLF motions no clear effect of the directional spread was found in the range tested here.
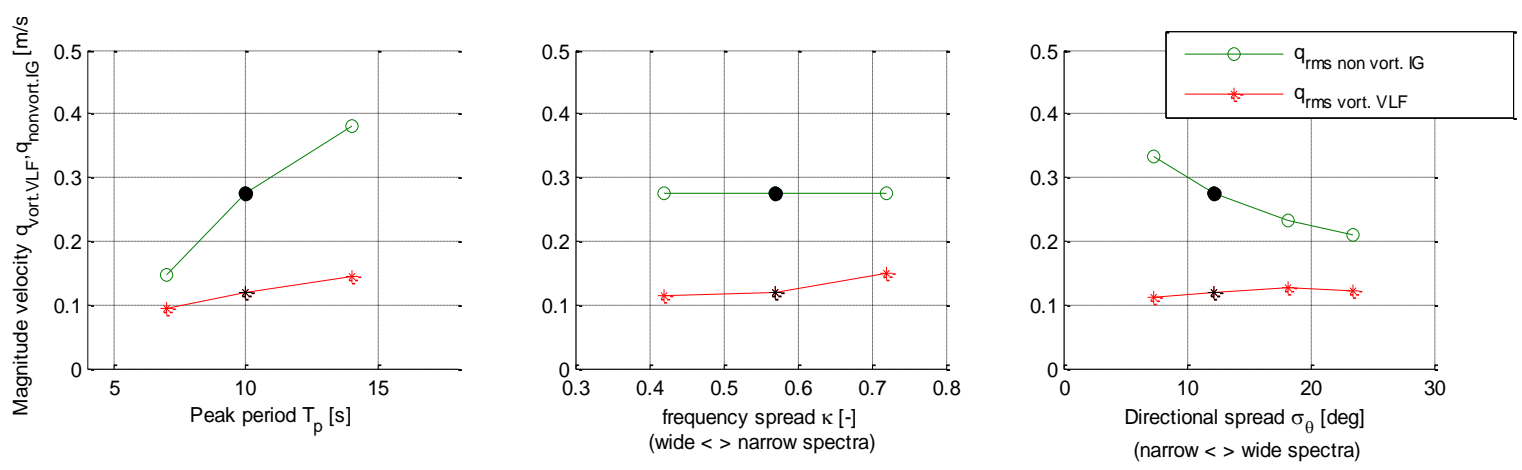

Figure 8. Vortical VLF (red) and non-vort. IG (green) velocity magnitude on the bar crest. Model results show how wave period (left), frequency spread (middle) and directional spread (right) differently affect the magnitude of both components. Black symbols show the reference scenario.

Overall, the model results show that even for a single wave height, the Vort VLF magnitude can vary significantly. For a single waveheight offshore the magnitude of VLF velocity fluctuations can differ significantly depending on the incident wave spectrum. These findings are analogous to the results of the observations at Duck, NC. Vortical VLF magnitude values vary about $50 \%$ of the magnitude itself, which partly explains the large scatter found in the observed vortical VLF magnitude for a single wave height. Combining the effect of all parameters, vortical VLF motions are expected to be stronger under swell conditions than under wind sea states, at least for the shore-normal case investigated here.

As mentioned, double peaked spectra appear in bulk parameters used here as wide spectra. To test whether bi-directional narrow peaked spectra yield also to strong vortical VLF motions, as hypothesized by Dalrymple (1975), more testing needs to be done in the future.

\section{CONCLUSIONS}

The objective of the current study was to investigate whether the magnitude of vortical very low frequency (VLF) velocity fluctuations under shore-normal waves are dependent on the type of wave conditions.

Sandy Duck field observations are examined to investigate the magnitude of vortical VLF motions under different offshore wave forcing. The observations show stronger vortical VLF motions under long wave period and narrow frequency spread waves.

Numerical model simulations investigating the effect of the incident wave parameters in a more isolated way confirm the observed effect of frequency spread and wave period on the magnitude of VLF motions. Vortical VLF velocity fluctuations were found to vary significantly in magnitude when the characteristics of the incident wave spectrum were changed.

These findings imply that under shore-normal incident waves strong vortical VLF motions are more likely under swell wave conditions than in windsea. Adding to previous findings, vortical very low frequency velocity fluctuations are therefore concluded to be ubiquitous under natural directionally spread waves, and their magnitude is dependent on the type of incident wave conditions.

\section{ACKNOWLEDGMENTS}

Elgar, Herbers, O'Reilly and Guza are acknowledged greatly for the Sandy Duck SPUV instrument data. We thank the Field Research Facility of the U.S. Army Engineer Waterways Experiment Station's Coastal Engineering Research Center is for the detailed bathymetries during Sandy Duck as well as making all data publicly available. Deltares, formerly Delft Hydraulics, is greatly acknowledged for the use of their Delft3D numerical model suite. We greatly appreciate the support of and discussions with 
Marcel Stive. Valuable comments by Bob Guza and Falk Feddersen after the conference were much appreciated and improved the manuscipt.

M.A. de Schipper is funded by Ecoshape/Building with Nature under Project Code NTW 3.2. The Building with Nature program is funded from several sources, including the Subsidieregeling Innovatieketen Water (SIW, Staatscourant nrs 953 and 17009) sponsored by the Dutch Ministry of Transport, Public Works and Water Management and partner contributions of the participants to the Foundation EcoShape. The program receives co-funding from the European Fund for Regional Development EFRO and the Municipality of Dordrecht. R. Ranasinghe and M. Stive are partly supported by the European Research Council under the European Community's Seventh Framework Programme (FP7/2007-2013) / ERC Grant agreement n [291206 ]-NEMO.

\section{REFERENCES}

Battjes, J. A., H.J. Bakkenes, T.T. Janssen, and A.R. van Dongeren. 2004. Shoaling of subharmonic gravity waves, J. Geophys. Res., 109.

Bowen, A.J., and R.A. Holman. 1989. Shear Instabilities of the Mean Longshore Current 1. Theory, $J$. Geophys. Res., 94.

Dalrymple, R.A. 1975. A mechanism for rip current generation on an open coast, J. Geophys. Res., 80.

Elgar, S., R.T. Guza, W.C. O’Reilly, B. Raubenheimer, and T.H.C. Herbers . 2001. Wave energy and direction observed near a pier, J. Waterw. Port Coastal Ocean Eng., 127.

Feddersen, F. 2004. Effect of wave directional spread on the radiation stress: comparing theory and observations, Coastal Engineering, 51.

Guza, R.T., and E.B. Thornton. 1980. Local and Shoaled Comparisons of Sea Surface Elevations, Pressures, and Velocities, J. Geophys. Res., 85.

Holthuijsen, L. H., N. Booij, and T. H. C. Herbers. 1989. A prediction model for stationary shortcrested waves in shallow water with ambient currents, Coastal Engineering, 13.

Holthuijsen, L.H. 2007. Waves in oceanic and coastal waters Cambrigde University Press

Johnson, D., and C. Pattiaratchi . 2004. Transient rip currents and nearshore circulation on a swelldominated beach, J. Geophys. Res., 109.

Kuik, A. J., G. P. van Vledder, and L. H. Holthuijsen. 1988. A method for the routine analysis of pitchand-roll buoy data, J. Phys. Oceanogr., 18

Long, C. E., and J. Atmadja. 1994. Index and bulk parameters for frequency directional spectra measured at CERC Field Research Facility, September 1990 to August 1991, Misc. Pap. CERC 945.

Longuet-Higgins, M.S. and R.W. Stewart, 1962. Radiation stress and mass transport in gravity waves, with application to surf beats. Journal of Fluid Mechanics, 13

MacMahan, J.H., A.J.H.M. Reniers, E.B. Thornton, and T.P. Stanton. 2004. Surf zone eddies coupled with rip current morphology, J. Geophys. Res., 109.

MacMahan, J.H., E.B. Thornton, and A.J.H.M. Reniers. 2006. Rip current review, Coastal Engineering. 53.

MacMahan, J.H., A.J.H.M. Reniers, and E.B. Thornton. 2010. Vortical surf zone velocity fluctuations with 0(10) min period, J. Geophys. Res., 115.

Reniers, A.J.H.M., J.A. Roelvink, and E.B. Thornton. 2004. Morphodynamic modeling of an embayed beach under wave group forcing, J. Geophys. Res., 109.

Reniers, A.J.H.M., J.H. MacMahan, E.B. Thornton, and T.P Stanton. 2007. Modeling of very low frequency motions during RIPEX, J. Geophys. Res., 112.

Reniers, A.J.H.M., J.H. MacMahan, E.B. Thornton, T.P. Stanton, M. Henriquez, J.W. Brown, J.A. Brown, and E. Gallagher. 2009. Surf zone surface retention on a rip-channeled beach, J. Geophys. Res., 114.

Reniers, A.J.H.M., J.H. MacMahan, F.J. Beron-Vera, and M.J. Olascoaga. 2010, Rip-current pulses tied to Lagrangian coherent structures, Geophys. Res. Lett., 37.

Sand, S. E. 1982. Long waves in directional seas, Coastal Enineering., 6.

Spydell, M.S., F. Feddersen, R.T. Guza, and W.E. Schmidt. 2007. Observing surf-zone dispersion with drifters. J. Phys. Oceanogr.,37.

Spydell, M.S., and F. Feddersen. 2009. Lagrangian drifter dispersion in the surf zone: Directionally spread, normally incident waves, J. Phys. Oceanogr., 39.

Van Dongeren, A., A. Reniers, J. Battjes, and I. Svendsen. 2003. Numerical modeling of infragravity wave response during DELILAH, J. Geophys.Res., 108. 
van Vledder, G.P. 1992, Statistics of wave group parameters, Proceedings of the International Conference on Coastal Engineering; No 23. 